\title{
CACIQUES Y CABILDOS: ORGANIZACIÓN SOCIO-POLÍTICA DE LOS PUEBLOS DE INDIOS EN LA ALCALDÍA MAYOR DE SONSONATE (S. XVI) ${ }^{1}$
}

\author{
POR
}

MERITXELL TOUS

Universidad de Barcelona

Este estudio analiza los mecanismos desarrollados en el siglo XVI por el grupo Pipil de la región de los Izalcos que les permitieron mantener, aunque no en su totalidad, los aspectos esenciales de su organización socio-política prehispánica. Las autoridades tradicionales (caciques y principales) desempeñaron un papel fundamental en la adecuación de dicho sistema al modelo castellano impuesto, el cabildo indígena. También se demuestra cómo dicha institución, a pesar de ser totalmente ajena al orden prehispánico, constituyó una pieza clave para la supervivencia de su organización socio-politica tradicional.

Palabras Clave: Pipil, Izalco, Alcaldía Mayor de Sonsonate, organización socio-política.

\section{INTRODUCCIÓN}

En época colonial, el actual territorio de El Salvador se hallaba dividido en dos Alcaldías Mayores: la de Sonsonate, que incluía aproximadamente los actuales departamentos de Sonsonate y Ahuachapán; y la de San Salvador, bajo cuya administración se hallaba el resto del territorio. Posteriormente, esta última se fragmentó en tres Alcaldías Mayores: la del mismo nombre, la de San Miguel y la de San Vicente. Dicha división permaneció intacta hasta 1786, al crearse la Intendencia de San Salvador, favoreciendo la administración de la

1 Trabajo que se inscribe en el proyecto de investigación coordinado por Pilar García Jordán, Región versus Estado: organización social y representación política en el Estado Liberal Latinoamericano, 1870-1930 c. Un estudio comparado, financiado por la Secretaría de Estado de Universidades, Investigación y Desarrollo BHA 2003-03628. 
zona, y paliando el excesivo centralismo político y económico desarrollado desde Santiago de los Caballeros a lo largo de los siglos XVI y XVII². La lejanía respecto a la capital de la Provincia y de la Audiencia supuso no sólo un menor control de las autoridades coloniales, sino también una vez concluido el ciclo económico del cacao, su lenta transformación en una zona marginal. Este hecho favoreció la continuidad no exenta de grandes transformaciones de determinados elementos culturales cuyo origen se halla en el mundo prehispánico.

El establecimiento de la Audiencia de Guatemala en 1544 produjo una reorganización del espacio centroamericano ${ }^{3}$. La desaparición de la mayor parte de las antiguas gobernaciones comportó problemas administrativos, puesto que el territorio era demasiado extenso para ser gobernado directamente por dicho tribunal. En consecuencia, se crearon unidades administrativas de menor tamaño como la Alcaldía Mayor de Sonsonate. Teniendo en cuenta la elevada población indígena que ocupaba dicha zona, la categoría administrativa que le hubiera correspondido era la de Corregimiento. No obstante, las autoridades coloniales primaron el factor económico y el estratégico. Sobre el primero es importante señalar que Sonsonate fue la principal área productora de cacao durante el siglo XVI, incluso mayor que el Soconusco guatemalteco ${ }^{4}$. Y respecto al segundo, dicha alcaldía garantizó el control del puerto más importante de la región, Acajutla 5 .

La capital de la Alcaldía se llamó Villa de la Santísima Trinidad de Sonsonate. De su fundación destacan especialmente cuatro aspectos. En primer lugar, su tardía constitución en el año $1552^{6}$ por orden de la Audiencia de Guatemala y de manos del Oidor Pedro Ramírez de Quiñónez ${ }^{7}$. Como es sabido, tras

2 En este sentido cabe indicar las fricciones entre las autoridades del Cabildo de Sonsonate y el de Guatemala. Así, en 1577, el Alcalde Mayor de Sonsonate no permitió a Diego de Guzmán (Alcalde Ordinario de Guatemala) portar la vara en los pueblos que tenía en encomienda en Izalcos. De forma similar, aunque con rotura de vara, sucedió en 1582 entre el Alcalde Mayor de Sonsonate y el Ordinario de Guatemala en Lardé y Larín, 1957: 475-476.

3 Para más información sobre la fundación de la Audiencia de Guatemala así como de sus presidentes y capitanes generales, véase las obras de Sherman, 1977: 192-198; Macleod, 1973: 390-392; y Molina, 1949.

4 A ello hemos de sumarle la abundancia de otros productos como el bálsamo. La zona suroeste era conocida como «la costa del bálsamo».

5 Según carta de Francisco de Magaña a la Corona, 18 de febrero de 1564, Archivo General de Indias, Sevilla (AGI), Audiencia de Guatemala, legajo 39 y López de Velasco, 1971: 150 , desde este puerto se comercializaban un total de 300.000 reales anuales de cacao, vía terrestre hacia Guatemala y marítima hacia el noroeste de México.

${ }^{6}$ López de Velasco, 1971: 150.

7 Para mayor información sobre Pedro Ramírez de Quiñónez, Oidor de la Audiencia de 
el periodo de conquista, a partir de la década de los cuarenta y gracias en buena medida a la promulgación de las Leyes Nuevas, el espacio colonial empezó a tejerse sobre rasgos más firmes y duraderos. En especial para América Central, éstas aportaron una mayor estabilidad a la zona tras la fundación de ciudades capaces de canalizar tanto el sistema administrativo y militar, como las actividades económicas.

En segundo y tercer lugar, la puesta en marcha de la República de Indios ideada por el primer Obispo de Guatemala, Don Francisco Marroquín. La finalidad de la misma fue garantizar, a partir de la separación de residencia, la conservación de la población indígena como cuerpo social dado el fracaso económico y demográfico derivado de la convivencia con los españoles ${ }^{8}$. No obstante, su fundación respondió básicamente a intereses económicos procedentes de Santiago de los Caballeros. En este sentido, Juan de Guzmán Alcalde Ordinario de esta ciudad, y uno de los mayores encomenderos de la zona junto al Alcalde Mayor de Acajutla (sobrino del Obispo Marroquín) entraron en conflicto con los comerciantes y mercaderes residentes en los pueblos de los Izalcos. Dada la injerencia de estos últimos, fueron expulsados de dichos pueblos y fundaron el asentamiento legal y permanente de Sonsonate. Su población era de 400 vecinos españoles (población total de 2.000 individuos), «todos ellos mercaderes y tratantes de cacao, pero ninguno encomendero» ${ }^{9}$. A pesar de ello, según se desprende de la documentación correspondiente a los distritos productores de cacao, durante el siglo XVI y principios del XVII, la presencia de españoles, mestizos, mulatos y negros en los pueblos de indios era un hecho, poseyendo incluso el beneplácito de las autoridades de la Audiencia ${ }^{10}$.

En cuarto lugar, señalar que al tratarse de encomiendas muy ricas, inicialmente se hallaban en manos de los principales jefes de conquista y familiares residentes en Santiago de los Caballeros ${ }^{11}$, ni tan siquiera en San Salva-

Guatemala, durante el mandato de sus dos primeros presidentes, véase Sherman, 1977: 141-143.

8 Véase, por ejemplo, los daños producidos a la población indígena en Carta del Obispo Marroquín a la Corona, 20 de febrero de 1542, AGI Patronato, legajo 184, ramo 35.

9 López de Velasco, 1971: 150. En 1556 ya tenía 120 casas de mercaderes y tratantes, $A u$ diencia de Guatemala a la Corona, 21 de abril de 1556, AGI Audiencia de Guatemala, legajo $9 \mathrm{~A}$, ramo 22, número 88.

10 Pineda, 1982 y Carta de Manuel de Ungría Girón a la Corona, 20 de marzo de 1605, AGI, Audiencia de Guatemala, legajo 12, ramo 2, número 12.

11 Ejemplo de ello lo constituyen la confirmación de encomienda de Fernando de Gálvez sobre Caluco (1605), Archivo General de Centroamérica, Guatemala (AGCA), Colonial, Superior Gobierno, Nombramientos, legajo 1751-11737; las querellas entre encomenderos como la 
dor. Tras la muerte de éstos y la fundación de la Audiencia de Guatemala, su primer presidente, Alonso de Maldonado procedió a su repartimiento entre amigos influyentes y parientes ${ }^{12}$. A partir de la capitalización de dichas encomiendas, se consolidó el denominado "Grupo de Salamanca» ${ }^{13}$ como el grupo político y económico más importante. Ejemplo de ello lo son D. Francisco Xirón y D. Juan de Guzmán, ninguno de ellos conquistadores ${ }^{14}$. El primero, encomendero de un cuarto de Caluco y la mitad de Nahulingo. Y el segundo, primo hermano o sobrino de Alonso de Maldonado ${ }^{15}$, además de encomendero de Tecpan Izalco y de la mitad de Nahulingo, también fue nombrado Procurador General del Cabildo de Guatemala ante la corte.

Dentro de la Alcaldía Mayor de Sonsonate, este estudio analiza la región de los Izalcos cuyo núcleo principal lo constituían Izalco (Tecpan Izalco), Caluco (Caluco Izalco), Naolingo y Tacuscalco (hoy extinto). El Licenciado Palacio sostiene que la «Provincia de los Izalcos es la cosa más rica y gruesa que vuestra majestad tiene en estas partes. (...) la más abundante de cacao que se sabe» ${ }^{16}$. Además, las tasaciones del Licenciado Cerrato de $1548-49^{17}$ revelan que de los 15 asentamientos pipiles de la región de los Izalcos, 13 de ellos tributaban un total de 3.660 Xiquipiles $^{18}$.

de Diego de Herrera y Pedro Girón (1599), AGCA Colonial, Superior Gobierno, Juicios ejecutivos, legajo 5905-50029; y los testamentos como el de Gaspar de Cepeda (1567), AGCA Colonial, Superior Gobierno, Juzgado de bienes de difuntos, legajo 365-4171.

12 El Licenciado López de Cerrato denunció esta situación en una carta dirigida al Rey el año 1549. En la misma, se señala explícitamente que no sólo «él tenia indios de encomienda (sino también), su suegro, y sus cuñados y hermanos», Colección Somoza, volumen 15, 1954-57: 31-41.

13 Este grupo, formado por D. Francisco Xirón, D. Juan de Guzmán y Juan Vázquez de Coronado, fue tejido por el propio presidente Maldonado, natural de Salamanca y miembro de su nobleza. A partir de una compleja red de conexiones y matrimonios - como el suyo propio - controló gran parte de la vida política y económica de Centroamérica, Sherman, 1979: 136-137.

14 Carta de Juan Mexía a la Corona, 30 de julio de 1577, AGI Audiencia de Guatemala, legajo 9 A, ramo 23, número 93.

15 Juicio de residencia de Alonso de Maldonado, 1548, AGI Justicia, legajo 299A o Juicio de Residencia de López de Cerrato, 1553, AGI Justicia, legajo 301. Además compró barcos para ampliar su negocio de venta de cacao hacia Nueva España y, cuando regresó a España lo hizo con 70.000 pesos y formó dos mayorazgos, en Macleod, 1973: 86.

16 García de Palacio, 1881: 15.

17 Tasaciones de los naturales de las Provincias de Guatemala realizadas por el presidente de la Audiencia, Licenciado Cerrato, 1548-1551, AGI Audiencia de Guatemala, legajo 128 .

181 xiquipil equivale a 8.000 almendras con un peso de $8,7 \mathrm{~kg}$, por lo tanto tributaban $31.842 \mathrm{~kg}$. 
Para finalizar este apartado, cabe hacer una breve referencia a las diversas fuentes empleadas en este estudio. En primer lugar, los aportes del grupo de investigadores que han centrado sus estudios arqueológicos y etnohistóricos de la zona Occidental de El Salvador, en especial los de carácter etohistórico e histórico de la Alcaldía Mayor de Sonsonate. En segundo lugar se ha acudido a las fuentes criollas y europeas impresas, cuya cronología va desde la propia conquista hasta el siglo XVIII, de entre todas ellas destacan las Relaciones Geográficas. Y, en tercer lugar, la base documental de este trabajo lo constituye el análisis de documentación inédita localizada en tres archivos: el Archivo General de Indias en Sevilla, el Archivo General de Centroamérica en Guatemala Ciudad ${ }^{19}$, y el Archivo General de la Nación en San Salvador ${ }^{20}$.

\section{ORganiZaCiÓn SOCIO-POLÍtiCA EN El SEÑORÍO DE IZALCO, Siglo XV}

Para hacer una correcta valoración de los procesos de cambio y/o continuidad del modelo de organización socio-política pipil tras la creación de los pueblos de indios, es absolutamente necesario conocer cuáles fueron los planteamientos socio-políticos de la zona en época prehispánica. Únicamente desde esta amplia perspectiva temporal podremos analizar con éxito dicho proceso.

Los habitantes que hallaron los europeos en la región de los Izalcos no constituían la población originaria. Los pipiles, grupo de habla nahuat, procedían del Altiplano Central y del área del Golfo de Mesoamérica, e iniciaron sus migraciones sobre el $800 \mathrm{~d}$. C., aunque según los datos glotocronológicos, el grueso mayor de la misma se produjo entre el 1000 y $1200 \mathrm{~d}$. C. Una parte de los pipiles se situaron en el territorio comprendido entre los ríos Paz y Lempa. Allí se erigieron dos señoríos principales, Cuzcatlan e Izalcos, que fungían

19 Informes oficiales, Tasaciones y Visitas constituyen la base documental de este estudio. En orden de importancia, le siguen la documentación gubernativa y judicial que incluye concesiones o confirmaciones de encomiendas, cartas remitidas por las autoridades o cartas de relación, cartas escritas por el Cabildo Secular y por religiosos e informaciones de Oficio y Parte. También fueron de interés el análisis de Autos Fiscales, Juicios de Residencia, de Probanzas de Méritos, así como de los pleitos seguidos contra los principales encomenderos de Guatemala.

20 Sobre este archivo, cabe señalar la escasa documentación correspondiente al siglo XVI de la Alcaldía Mayor de Sonsonate. Ello es debido, en primer lugar, al hecho de que dicha Alcaldía, desde el punto de vista administrativo, pertenecía a la Provincia de Guatemala, por lo que la mayor parte de la documentación era enviada a Santiago de los Caballeros. En segundo lugar, a la historia convulsa de El Salvador entre los años 1979 y 1992 que comportó la pérdida de numerosa documentación, en especial del siglo XVIII. Y en tercer lugar, a los desastres naturales que periódicamente han asolado la región. 
como cabeceras, y que obviamente contaban con diferentes cacicazgos dependientes. Para el caso concreto de los Izalcos, allí se conformó uno de los esta$\operatorname{dos}^{21}$ más poderosos del suroeste de Mesoamérica que contaba con 15 asentamientos principales, un territorio de $2.500 \mathrm{~km}^{2}$ y una población estimada, en 1519 , de 54.000 individuos.

La sociedad pipil se caracterizó por su complejidad y estratificación. William Fowler ${ }^{22}$ sostiene que se trata de una sociedad plenamente estatal con un acceso diferenciado al poder, al prestigio y a la propiedad. Dicha sociedad se organizaba en torno al calpulli, definido como la unidad gentilicia base y/o una unidad territorial-administrativa. Ya fuese una institución de origen social o político, hecho muy discutido ${ }^{23}$, lo cierto es que entre los pipiles, su cohesión se vio fortalecida por: la tenencia de tierras, repartidas y distribuidas entre sus miembros para su producción; la existencia de una estratificación interna con base al parentesco y de una dirección política ejercida por el señor mayor del linaje; $y$, posiblemente, la existencia de un dios patrono que determinaba la actividad principal de sus componentes.

Un ejemplo de la división interna de cada comunidad en diferentes calpullis lo constituía el pueblo de Caluco, dividido en 5 calpullis, cada uno con su propio cacique o cabeza titular. Otro ejemplo aún más interesante, es la creación por razones tributarias de los llamados «pueblos gemelos», como lo fueron Naolingo y Tacuscalco. Entre 1580-81 se sucedieron una serie de pleitos entre ambos pueblos por el uso de tierras comunales y de los huertos de ca$\mathrm{cao}^{24}$. En una carta enviada por el gobernador del primero hacia el segundo se hace hincapié en su parentesco común

Nuestras madres, nuestros padres eran de una comunidad llamada tlacuchcal, fue debido a los españoles que ahora la comunidad está dividida y pues aún estamos. Usted guarda su pueblo y mi hermano menor el otro.

En este pleito se observa cómo los españoles aprovecharon las divisiones comunitarias autóctonas al dividir estos pueblos y darlos a Bonifacio Mexía y Juan Gálvez, posiblemente miembros de un solo o de dos altos linajes prehispánicos ${ }^{25}$. En consecuencia, a pesar de que los españoles modificaron las cate-

21 Para la definición de estado, véase las obras de Carneiro, 169 (1970): 733-738, y Service, 1984.

22 Fowler, 1989: 192.

23 Para mayor información sobre las características del Calpulli, véase los trabajos de Carrasco, 1996: 317-326; López Austin y López Luján, 1996: 199.

24 Pleito entre los indios de Tacuscalco y los de Nahulingo, 1580-1581, AGCA Colonial, Superior Gobierno, Misiones y reducciones de indios, legajo 674-6178.

25 Fajardo, 1993: 53. 
gorías preexistentes, de calpullis se pasó a pueblos, designando para cada una de las mitades a gobernadores de alta ascendencia prehispánica.

En esta sociedad convivieron dos grandes grupos sociales: la gente común y los nobles. La pertenencia a uno u otro grupo venía dada desde el nacimiento. No obstante, las posiciones de alto rango debían de ser validadas por el Consejo, existiendo una movilidad social de carácter vertical gracias a los méritos alcanzados en el campo de batalla o en el Consejo.

Los nobles ocupaban los más altos cargos políticos y religiosos. En el vértice superior se situaba el «cacique mayor» ${ }^{26}$ que intervenía en la mayor parte de los aspectos de la vida de sus comunidades, tales como la presidencia del Consejo, la toma de decisiones sobre la guerra, el bienestar común y la celebración de ciertas ceremonias. Su lugar de residencia era la capital del estado o provincia, es decir, Izalco. Dicha capitalidad, además de confirmarse a partir de los estudios arqueológicos, viene avalada también por la documentación colonial, que se refiere a ésta como Tecpan Izalco. Pedro Carrasco ${ }^{27}$ afirma que el término nahua de tecpan hace referencia a un territorio mayor que incluye diversos señores locales, es decir, un dominio sobre una extensa región. Por lo tanto, podemos afirmar que Izalco fue la sede de un noble linaje. Otros miembros de la nobleza tales como caciques menores, capitanes de guerra, confesores y sacerdotes formaban parte del Calpuleque (dirigentes del calpulli).

Un aspecto fundamental fue la existencia de un Consejo llamado Tatoque que servía de soporte al cacique y estaba constituido por ocho miembros cuidadosamente escogidos entre los individuos de mayor rango de la comuni$\mathrm{dad}^{28}$. La continuidad de dicho consejo, aunque modificada y reconducida hacia la estructura del cabildo, se confirma en una carta de $1629^{29}$ en que los alcaldes y tatoques de Izalco piden que dicho pueblo sea contado de nuevo.

Para terminar este apartado, cabe señalar brevemente el uso y la tenencia de la tierra. Esta última fue controlada por el segmento dominante, siendo privilegio del soberano asignar el uso de las tierras comunales a los jefes de cada calpulli, y haciendo éstos lo mismo entre sus subordinados. Entre las tierras controladas y propiedad del segmento dominante, destacan aquellas dedicadas

26 A diferencia de otros grupos, no tenemos noticia alguna del término empleado para designar a esta figura. La única referencia hallada está fechada en 1580-81, en la que los dirigentes de la zona de los Izalcos se hacen llamar tlatoani. Pleito entre los indios de Tacuscalco y los de Nahulingo, 1580-1581, AGCA Colonial, Superior Gobierno, Misiones y reducciones de indios, legajo 674-6178.

27 Carrasco, 1976: 21-24.

28 Fuentes y Guzmán, 1972: 58.

29 Carta de los alcaldes y tatoques de Izalco a la Corona, 1629, AGCA Colonial, Real Hacienda, Reales tributos y encomiendas, legajo 534-5967. 
al cultivo del cacao. Este fruto, elemento clave dentro de la economía mesoamericana, era pagado como tributo y según los pleitos seguidos contra Don Diego de Guzmán ${ }^{30}$ por el Fiscal de la Audiencia de Guatemala, el cacique de Izalco poseía «Gran número de huertas de cacao, más que ningún otro pueblo de la región».

3. ORGANIZACIÓN SOCIO-POLÍTICA EN LOS PUEBLOS DE INDIOS DE LA REGIÓN DE LOS IZALCOS, SIGLO XVI

Antes de proceder al análisis de la organización socio-política de los pueblos de indios, es importante destacar que, según la concepción de la propia sociedad en el Antiguo Régimen ${ }^{31}$, a la población indígena se la equiparó con un órgano o cuerpo social ${ }^{32}$, que en su caso correspondía a los pies. Por un lado, esta parte del cuerpo era fundamental, puesto que de ellas dependía el soporte y el sustento de todo el cuerpo, pero por otro se la consideraba inferior, puesto que eran los pies ${ }^{33}$. Esta concepción es de vital importancia para comprender el funcionamiento de dicha sociedad, pues al tratarse de una de tipo corporativo, cada cuerpo social precisaba de un margen de autonomía para llevar a cabo su función. En consecuencia, los pueblos de indios gozaron de un margen de autonomía notable, y fue precisamente en su funcionamiento donde se perpetuaron ciertos aspectos de la tradición prehispánica ${ }^{34}$.

Según Real Provisión del 21 de marzo de $1551^{35}$, la creación de los pueblos de indios tuvo como principal objetivo la evangelización y la educación de la población indígena. No obstante, también cabe considerar otros aspectos. Entre ellos, el control político, de la mano de obra (repartimiento de labores) y

30 Pleitos seguidos por el Fiscal de la Audiencia de Guatemala contra Diego de Guzmán, 1582-1585, AGI, Escribanía de Cámara, legajo 331A.

31 Mientras Stephen Webre (1993) sostiene el desarrollo de un estado centralizado en el Antiguo Régimen, José Martínez Millán (1994 y 2000), entre otros, aboga por el desarrollo de un sistema de cortes reales interconectadas que perduró durante toda la Edad Moderna. Por lo tanto, dicho historiador afirma que la corte se convirtió en una pieza clave en la «trabazón y funcionalidad del Imperio».

32 Podemos argumentar la consideración de la población indígena como un cuerpo social a partir del análisis de su estatus jurídico como vasallos libres de la Corona ya desde 1500, pasando por las Leyes de Burgos hasta la Recopilación de 1681.

33 Alda Mejías, 2002: 37-43.

34 Tanck Estrada, 2005: 22-27.

35 Konetzke, 1953: 283-284. 
del tributo, la necesidad de conservar a los indígenas como cuerpo social, y en especial, la creación de una figura alternativa a la de los dirigentes tradicionales que fungiera de intermediario entre la población indígena y los «nuevos señores» ${ }^{36}$. Este último aspecto resultó clave para las autoridades civiles y religiosas, puesto que el cabildo podía erigirse como alternativa al liderazgo de caciques y principales.

En la región de los Izalcos, los primeros pueblos de indios se constituyeron en 1548, durante el mandato del presidente López de Cerrato ${ }^{37}$. A diferencia de otras zonas, tal cometido recayó en el clero secular ${ }^{38}$. Éstos iniciaban conversaciones con los caciques y principales para obtener su favor ${ }^{39}$, escogiéndose a continuación un lugar, y una vez asentados, se sembraban las tierras y se iniciaban las obras de construcción de la iglesia, de la casa del cura u otra edificación ${ }^{40}$. Según el Padre Vitoria ${ }^{41}$ cada República era concebida bajo el principio de autosuficiencia (humano, material, jurídico y político). En consecuencia, cada pueblo tenía sus propias autoridades, tierras y jurisdicción. No obstante, dicha independencia debe de ser matizada, puesto que en realidad existió una constante injerencia en su funcionamiento tanto por parte de las autoridades civiles como de las religiosas ${ }^{42}$.

Al frente de cada pueblo de indios existía una cabecera cuya jurisdicción difería según su tamaño. Por lo general, ésta se subdividía en barrios o parcialidades que, a su vez, tenían jurisdicción sobre diferentes aldeas o es-

36 Además de los factores aducidos, Tanck Estrada, 2005: 26, sostiene que la tradición urbana de la Península Ibérica también desempeñó un papel fundamental en la creación de los pueblos de indios.

37 En este sentido, cabe señalar que uno de los principales escollos para su desarrollo, el propio Pedro de Alvarado, había muerto. Sobre las reformas impulsadas por el Presidente López de Cerrato, así como de las reacciones que de su implantación se derivaron, véase Sherman, 1979: 136-137 y Macleod, 1973: 96-119.

38 Fray Tomás de la Torre, según carta dirigida al Consejo de Indias en el año 1553, denuncia la mala conducta de los curas de Izalco y Tascuscalco e insta la construcción de un convento de franciscanos o dominicos. Fray Tomás de la Torre al Consejo de Indias, 22 de mayo de 1553. AGI, Audiencia de Guatemala, legajo 8.

39 Remesal, 1964: 154.

40 En la Recopilación de Leyes de los Reynos de las Indias, Título 3, Libro VI se hallan recogidas 29 leyes sobre las características de los pueblos de indios.

41 Vitoria, 1974: 80.

42 En este sentido, también cabe recordar la injerencia que practicaron, tanto las autoridades civiles como las eclesiásticas, sobre la economía de los pueblos de indios. Aunque sin éxito alguno, para abortar dicha práctica se dictaron numerosas Reales cédulas como la de 1575, AGCA Colonial, Superior Gobierno, Reales cédulas, legajo 1519; la de 1582, AGCA Colonial, Superior Gobierno, Reales cédulas, legajo 1513; y la de 1605, AGCA Colonial, Superior Gobierno, Reales cédulas, legajo 1514. 
tancias ${ }^{43}$. A pesar de la existencia de dicha gradación, esta investigación se ha centrado en las cabeceras, puesto que en ellas convivieron dos órganos distintos no necesariamente divergentes, el cabildo indígena y el cacicazgo, que compartían funciones tales como la distribución de la tierra o la vigilancia de la conducta de los indios.

La primera de estas instituciones fue el cabildo indígena cuya organización siguió el modelo de Castilla. Aunque con ciertas variantes, según la importancia o tamaño del pueblo, cada cabildo se hallaba integrado por un alcalde, un número variable de regidores, alguaciles y mayordomos, y un escribano. Dichos cargos eran elegidos anualmente entre los miembros de la comunidad ${ }^{44}$. $\mathrm{Su}$ función general fue la de garantizar el buen funcionamiento de la comunidad con jurisdicción sobre aspectos políticos, económicos, administrativos, fiscales, e incluso judiciales en casos civiles y criminales de pequeña importancia. Tres fueron sus principales escollos frente a la figura del cacique: su carácter anual, su acceso restringido a la fuerza de trabajo, y en muchos casos, la ausencia de carisma.

Dentro de la composición del cabildo indígena sobresale la figura del Gobernador de indios, como juez y pacificador de diferencias. Dicho cargo era designado por la Audiencia a propuesta y recomendación de los caciques y principales de una comunidad. Es por ello que, en la mayoría de los casos, fue ocupado por aquellos individuos de mayor rango.

La segunda institución la constituyó la nobleza indígena. Tras la Conquista, la monarquía hispana no sólo reconoció su existencia, sino que la integró en una nobleza local. Este hecho fue fundamental, puesto que la Corona a la vez que reprodujo dentro de la República de Indios una sociedad jerarquizada acorde con su visión estamental, perpetuó parte de la organización socio-política prehispánica.

A grandes trazos, dicha nobleza indígena no constituía un grupo homogéneo, sino que al igual que en tiempos pretéritos, estaba integrada por caciques y principales, «(...) los principales y calpules mandan con despotismo» ${ }^{45}$. So-

43 La Real Cédula dirigida a la Audiencia de los Confines para que investigue sobre el modo de tributación y régimen de propiedad prehispánicos, 1553, AGCA Colonial, Superior Gobierno, Reales cédulas (Audiencia), legajo 4575, constituye un ejemplo del interés que suscitó el conocimiento, con fines totalmente prácticos, sobre la organización política prehispánica tanto a nivel local como supralocal.

44 Dorothy Tanck, 2005: 27 sostiene que el grupo de electores con derecho a voto estaba constituido por un número reducido de hombres nobles o ancianos. No obstante, en ciertos pueblos se permitía votar a un mayor número de tributarios y, en ocasiones a todos los varones mayores de 18 años.

45 Cortés y Larraz, 2001: 105. 
bre la existencia de ambas categorías ${ }^{46}$ no existe un consenso entre los historiadores puesto que, en determinadas áreas, la imposición de los cabildos indígenas comportó la desintegración de la organización supralocal prehispánica. En consecuencia, los caciques no sólo redujeron su espacio de influencia, sino que pasaron a compartir su poder, para finalmente fusionarse con los principa$\operatorname{les}^{47}$. En la región de los Izalcos, a pesar de que dicha organización supralocal quedó muy diezmada, podemos afirmar que parte de la misma, así como de sus dirigentes, se perpetuaron gracias al mantenimiento o creación de unidades menores dependientes como parcialidades y barrios.

En cuanto a los caciques, la Corona sostuvo que eran los «señores naturales $\rangle^{48}$ y gobernantes de sus territorios, por lo que fueron equiparados a la nobleza baja peninsular ${ }^{49}$. Se hallaban exentos de pagar tributo, poseían el título de Don, conservaron parte de su patrimonio y siervos, se les concedieron escudos de armas y blasones distintivos, y hasta 1538, se les permitió administrar justicia. Su patrimonio se sustentaba en la propiedad y el terrazgo ${ }^{50}$, el cobro de tributos y los beneficios obtenidos de transacciones comerciales ${ }^{51}$. A diferencia del Alcalde de Indios, el cacique mantuvo un acceso directo a la fuerza de trabajo y a los tributos en sus comunidades. Un aspecto muy importante de la evolución del cacicazgo fue su carácter vitalicio y su transmisión según las leyes que regían los mayorazgos castellanos (Real Cédula del 26 de marzo de 1697). Ambos aspectos supusieron una grave perturbación de los modelos prehispánicos. Respecto a la sucesión del cargo, no siempre recaía en el varón primogénito, sino que habitualmente se transfería al miembro más capaz del linaje. También se puso mayor énfasis en el gobierno en manos de varones y la sucesión por línea masculina, subestimándose el derecho femenino de acceso

46 El enfrentamiento entre Luis Pérez y Cristóbal Pérez, ambos indios principales de la misma comunidad, constituye un claro ejemplo de la rivalidad entre caciques y principales. Pleito entre indios principales, 1645, AGCA Colonial, Superior Gobierno, Juicios ejecutivos, legajo 4115-32596.

47 En este sentido, cabe añadir que las tierras del tecpan pasaron a manos de la elite local o de la comunidad.

48 No obstante, y debido a las presiones tanto de las autoridades civiles como religiosas, según Real Cédula de 1538 se substituyó el vocablo de «señores» por el de caciques en Recopilación de Leyes de los Reynos de las Indias, 1943, Ley 5, Tit. 7, Lib. VII.

49 No obstante, William Sherman, 1979: 285 sostiene que las autoridades hispanas infligieron constantes vejaciones a los caciques y gobernadores, ejemplo de ello fueron las agresiones que propició el Alcalde Mayor de la Trinidad a los gobernadores indios de Izalco y Tacuscalco.

50 Constituido por aquellos individuos que trabajan las tierras propiedad de los caciques en forma de usufructuarios y que debían tributar por ello.

51 Menegus, 2005: 25. 
a los cacicazgos ${ }^{52}$. En cuanto a la segunda categoría, los principales, constituyó la elite local. Según la documentación colonial, se les denominaba «jefes de cabeza de calpule», alusión inequívoca a los calpullis prehispánicos.

Tras la creación de los pueblos de indios, las comunidades se organizaron en torno a una sólida jerarquía. En este sentido, podemos afirmar que no se produjo una homogenización social, sino todo lo contrario, puesto que se perpetuaron las diferencias entre macehuales y principales. Tal y como se ha referido anteriormente, en época prehispánica la movilidad social era escasa, aunque posible. Las vías más comunes fueron la guerra o el sobresalir en el Consejo. A pesar de que la Conquista abrió nuevos canales como alianzas con conquistadores y/o encomenderos, el ascenso social nunca tuvo lugar a partir del sistema electo ${ }^{53}$. En consecuencia, fue precisamente la «nobleza de sangre» la que monopolizó los principales cargos del cabildo y no permitió su acceso a los macehuales $^{54}$. Así, el gobierno siguió vinculado a las dinastías o linajes más relevantes cuya legitimidad se fundamentaba en su origen. Es más, podemos afirmar que ambos organismos se retroalimentaron, pues fue precisamente a través de la institución hispana como la nobleza prehispánica reforzó su legitimidad y perpetuó las diferencias sociales ya preestablecidas.

A este aspecto hay que añadirle otro incluso más relevante, la propiedad de la tierra, y en especial la de los huertos de cacao. Si bien es cierto que la propiedad de la misma en los pueblos de indios era colectiva y distribuida por las autoridades del cabildo entre los indígenas como usufructuarios ${ }^{55}$, la región de los Izalcos constituyó una clara excepción. La nobleza indígena, como ya lo fue en época prehispánica, continuó siendo el principal poseedor de las tierras dedicadas al cultivo del cacao. Así, por ejemplo, en 1582 el gobernador de Caluco, Don Gregorio de Valencia, y su mujer Doña Francisca, eran dueños de 29 huertas de cacao, que producían 50 xiquipiles ${ }^{56}$. La misma tendencia se ob-

52 O'Phelan, 1997: 18.

53 Así, por ejemplo, los principales del pueblo de Cuyotenango (Guatemala) se enfrentaron a Francisco Vázquez Xix con el fin de destituirle del cargo de alcalde puesto que se había hecho pasar por principal cuando en realidad era un macehual, 1639, AGCA Colonial, Superior Gobierno, Corregimientos, Alcaldías Mayores y Partidos, legajo 5532-47823.

54 No existió una regla general para todo el territorio americano. En algunos lugares no se implantó dicho sistema, en otros los cargos fueron ocupados por reservados de la iglesia, principales menores e incluso macehuales.

55 Según Real Cédula de 1682, ante necesidades de tipo coyuntural, los cabildos indígenas podían vender o alquilar propiedades a terceros. AGCA Colonial, Superior Gobierno, Reales cédulas, legajo 5322-44819.

56 Visita y tasación de los indios del pueblo de Caluco por el Licenciado Collazo, 1583, AGI, Justicia, legajo 334. 
serva en la documentación correspondiente a los pleitos seguidos contra Don Diego de Guzmán ${ }^{57}$ en la que se afirma que el cacique de Izalco en época de la Conquista era el propietario «de gran número de huertas de cacao, más que ninguna otra ciudad de la región».

El mantenimiento de dicha propiedad nos lleva a reflexionar en torno a la pervivencia de dos elementos más de origen prehispánico: el modelo de producción del cacao y el desarrollo de transacciones comerciales. Aunque no incidiré sobre el primero, cabe señalar que debido a la dificultad que conlleva su cultivo $^{58}$, se mantuvieron los modelos tradicionales de producción ${ }^{59}$. Respecto al desarrollo de actividades mercantiles, ya se ha señalado que los habitantes de la Villa de Sonsonate eran «todos ellos mercaderes y tratantes de cacao, pero ninguno encomendero». Siguiendo con el ejemplo de Caluco, la producción total de los huertos propiedad de Don Gregorio de Valencia y su mujer Doña Francisca, ascendía a 50 xiquipiles de cacao, mientras que el monto del tributo era de 20 xiquipiles $^{60}$. Los treinta sobrantes eran destinados no sólo al pago de quienes cultivaban las huertas, sino también a su venta en el mercado. Observamos cómo a pesar de los diferentes mecanismos de apropiación de la producción de cacao, la población indígena, y en especial la elite, logró comercializar parte de su producción, tal y como lo había hecho en época prehispánica.

A pesar de lo apuntado, muy a menudo no se produjo con éxito el acoplamiento, tanto entre la nobleza de sangre y los caciques, como entre la nobleza de sangre y las autoridades del cabildo. En cuanto el primero ${ }^{61}$, Margarita Menegus señala que la principal causa fue la propia concepción hispana sobre la nobleza. Ésta podía ser de sangre o de privilegio. Mientras que la primera era una nobleza de linaje, la segunda se creaba a voluntad del monarca y respondía a los servicios y méritos prestados al rey. Así, conquistadores y autoridades hispanas relevaron a los «señores naturales» que no les eran favorables e impusieron a

57 Pleitos seguidos por el Fiscal de la Audiencia de Guatemala contra Diego de Guzmán, 1582-1585, AGI, Escribanía de Cámara, legajo 331A.

58 Siembra individual, intercalado de madrecacao, riego casi permanente, desyerba y reemplazo constante de los árboles.

59 A pesar de que algunos encomenderos establecieron pequeñas haciendas y plantaciones cerca de los pueblos que tenían en encomienda, su producción fue casi insignificante. Tampoco existieron haciendas ganaderas. Tal y como señala López de Velasco, 1971: 150 «No consienten andar ganado dentro de esta provincia en veinte leguas que tendrá de contorno, por los cacaguales, y así se proveen de carne de fuera de la provincia».

60 Visita y tasación de los indios del pueblo de Caluco por el Licenciado Collazo, 1583, AGI, Justicia, legajo 334.

61 Menegus, 2005: 36. 
aquellos individuos que les habían ayudado o, simplemente eran más «dóciles». Son los denominados caciques intrusos o advenedizos. Según López de Cerrato «en toda esta provincia casi no hay cacique natural o legítimo» ${ }^{62}$. Es más, en el Libro Viejo de la Fundación de Guatemala ${ }^{63}$ se afirma que ciertos naborías designados por los españoles se convirtieron en verdaderos y temidos tiranos que «maltratan a los señores e naturales de los tales pueblos, atándolos e dándoles palos e bofetones e otros muchos malos tratamientos»

En referencia al acoplamiento entre la nobleza de sangre y las autoridades del cabildo, se puede afirmar que existió una injerencia de las autoridades civiles y religiosas a través de la imposición de candidatos para el cabildo, fraudes electorales o simplemente, a partir de la «supuesta» incorrecta interpretación de las leyes. Por ejemplo, en 1563 el licenciado Loaisa escribió a la Corona diciendo que se habían recibido nueve Reales Cédulas, entre las cuales se pide se dé relación de por qué la Audiencia permitió que los alcaldes ordinarios de villas (de españoles) sujetaran a los alcaldes de indios, teniendo en cuenta que por encima de éstos se hallaba únicamente la figura del Alcalde Mayor ${ }^{64}$.

Para finalizar, es importante tener en cuenta el desarrollo de la organización supralocal pipil, puesto que éste fue uno de los aspectos que sufrió mayores alteraciones durante el siglo XVI. Ello fue debido a que cada una de las estructuras señaladas (cabildo) se repitió en cada uno de los pueblos de indios. Es decir, el modelo anterior formado por una cabecera, Izalco, y 15 asentamientos tributarios dependientes fue disgregado al actuar cada concejo no más allá de su propia jurisdicción. A pesar de ello, una vez reunidos en un mismo pueblo, las comunidades indígenas a menudo conservaban su identidad autóctona y funcionaban como componentes individuales, es decir, las parcialida$\operatorname{des}^{65}$. Se trata de unidades sociales y territoriales de origen prehispánico, organizadas a partir de los calpullis. El ejemplo más claro lo constituye la descripción del Obispo Pedro Cortés y Larraz en la que se relacionan todas y cada una de las parroquias, pueblos y haciendas dependientes ${ }^{66}$.

Es más, si comparamos los linderos prehispánicos de Izalco (definidos a partir de la arqueología y la información colonial) con los de la Alcaldía Mayor de Sonsonate (definidos a partir de la Relación de Marroquín o las Tasa-

62 Colección de documentos inéditos relativos al descubrimiento, conquista y colonización de las posesiones españolas en América y Oceanía, sacados en su mayor parte, del Real Archivo de Indias, Vol. 24, 1864-1884: 262-63.

63 Libro Viejo de la Fundación de Guatemala, 1991: 94.

64 Cabrera, 2000: 448.

65 Lovell, 1990: 83.

66 A modo de ejemplo, en 1770 el pueblo de Caluco fungía como cabecera y de él dependían Naulingo, Guaimango, Juyuta y dos haciendas, Cortés y Larraz, 2001: 97. 
ciones de López de Cerrato del siglo XVI ${ }^{67}$, y aún más, de la visita de Pedro Cortés y Larraz del siglo XVIII) los cambios que se produjeron fueron mínimos. Los pueblos convergentes eran: Salcoatitan (Quezalcoatitlan), Acajuatla, Juayuá, Juxutla (Juayua), Ataco, Tacaba, Managua (Masahuat), Mecameos, Tacuscalco y Nahulingo (ambos pueblos gemelos), Tecpán Izalco (Izalco), Caluco, Xitaulco, Apaneca y Acatepeque. La excepción la constituye Nahuizalco y Santa Catarina Mazahuat, que en época prehispánica eran dos asentamientos del Señorío de Cuscatlan en territorio del Señorío de Izalco. Dicha excepción se debió a dos factores. Primero, a que dichos estados siguieron el modelo mexica de no continuidad espacial territorial, aunque sí económica. Y en segundo lugar, a que las fronteras de dichos estados no eran estáticas, y es más, posiblemente el Señorío de Cuscatlan a la llegada de los europeos se hallaba en expansión. La otra excepción la constituye Tacuscalco, el único pueblo de indios extinto. Por todo ello, podemos concluir que la frontera de la Alcaldía Mayor de Sonsonate delimitada desde el punto de vista jurisdiccional ${ }^{68}$, se corresponde en gran medida con la frontera histórica del Señorío de Izalco.

\section{CONCLUSIONES}

A diferencia de lo que sucedió en otras Provincias ${ }^{69}$, la adopción de la República de Indios en la región de los Izalcos no supuso la aniquilación de las comunidades indígenas, sino todo lo contrario. A partir de su implantación a mediados del siglo XVI y a lo largo de todo el periodo colonial, constituyeron un elemento fundamental en la construcción o reconstrucción de la identidad indígena, a la vez que se convirtieron en una entidad territorial, jurídica y políticamente activa ${ }^{70}$. Partiendo de la caracterización de las comunidades en época prehispánica y tras el estudio del funcionamiento de los pueblos de indios

67 Relación de Marroquín, 1532, AGI Audiencia de Guatemala, legajo 52 y Tasaciones de los naturales de las Provincias de Guatemala realizadas por el presidente de la Audiencia, Licenciado Cerrato, 1548-1551, AGI Audiencia de Guatemala, legajo 128.

68 Para definir la frontera jurisdiccional se han tenido en cuenta los siguientes ámbitos: político-administrativo, judicial, económico y religioso. De todos ellos, posiblemente el primero fue el ámbito más importante y se define, a grosso modo, a partir de la jurisdicción sobre los pueblos de indios.

69 El control y la constante injerencia, tanto de autoridades civiles como religiosas, en los pueblos de indios de la Provincia de Nicaragua, desvirtuó en gran medida la naturaleza de los mismos y como resultado de ello, las autoridades indígenas se convirtieron en simples marionetas al servicio de los intereses hispanos, en Tous, 2008: 395-407; 428-449.

70 Este último se observa a partir de los largos pleitos que mantuvieron con los encomenderos, autoridades civiles y religiosas, entre otros. 
en época colonial, he constatado que el sistema municipal, a pesar de tratarse de un modelo ajeno al propio, proporcionó la suficiente autonomía a la población indígena para realizar una lectura propia de las nuevas concepciones sociales, culturales y políticas. Es decir, nos hallamos frente a un complejo proceso de adaptación que provocó una profunda reformulación de la tradición prehispánica tras la adopción de nuevos conceptos socio-políticos.

Dicho proceso, definido por Nancy Farriss ${ }^{71}$ como «aculturación estratégica», busca hacer «algunos cambios» pero al mismo tiempo conservar elementos esenciales de la cultura prehispánica. A nuestro parecer, es una muestra más de la enorme capacidad que tuvo la población indígena de mantener vivas unas tradiciones de comportamiento que no sólo los vinculaba a su antigua cultura sino que también les aseguraba su supervivencia en la Colonia.

Es más, incluso podemos referirnos a una «aculturación estratégica» en sentido inverso, puesto que la Corona llegó a mantener ciertos aspectos de la denominada «Ley Natural». Así, por ejemplo, refiriéndose al gobierno de los pueblos de indios, la Ley 4, Título 1 del Libro II de la Recopilación de 1681 dispone «que se guarden las leyes que los indios tenían antiguamente para su gobierno y las que se hicieron de nuevo».

Por otro lado, al adoptar el sistema municipal, éste se convirtió en el nuevo mecanismo que sancionó el poder y la posición desigual de la elite prehispánica dentro de los pueblos de indios. Los caciques y principales continuaron manteniendo sus privilegios gracias a su árbol genealógico, y en especial para la provincia de los Izalcos, al mantenimiento de sus tierras.

\section{BIBLIOGRAFÍA CITADA}

Alda Mejías, Sonia, La participación indígena en la construcción de la República de Guatemala, S. XIX, Madrid, Ediciones de la Universidad Autónoma de Madrid, 2002.

Cabrera Rajo, Sigfredo, Los Alcaldes Mayores de la Provincia de San Salvador en el Siglo XVI, Barcelona, Universidad de Barcelona, Tesis inédita, 2000.

Carneiro, Robert, «A theory of the origin of the state», Science, 169 (1970): 733-738.

Carrasco, Pedro, «Los linajes nobles del México antiguo», Pedro Carrasco, et al. (eds.), Estratificación social en la Mesoamérica prehispánica, México, INAH, 1976.

- Estructura político-territorial del Imperio Tenochca. La Triple Alianza de Tenochtitlan, Tetzcoco y Tlacopan, Fideicomiso Historia de las Américas, Serie Hacia una Nueva Historia de México, México, Fondo de Cultura Económica, 1996.

71 Farriss, 1983: 34. 
Colección de documentos inéditos relativos al descubrimiento, conquista y colonización de las posesiones españolas en América y Oceanía, sacados en su mayor parte, del Real Archivo de Indias, bajo la dirección de J. F. Pacheco y F. Cárdenas, 42 vols. Madrid, 1864-1884.

Colección de documentos para la historia de la formación social de Hispanoamérica, 1493-1810, bajo la dirección de Richard Konetzke, 5 vols. Madrid, CSIC, 1953-1962.

Colección Somoza: documentos para la historia de Nicaragua, editado por A. Vega Bolaños, 17 vols., Madrid, 1954-57.

Cortés y Larraz, Pedro, Descripción geográfico-moral de la Diócesis de Guatemala, Madrid, CSIC, 2001.

Fajardo, Juan José, Monografía general de Nahulingo, San Salvador, Patronato ProPatrimonio Cultural, 1993.

Farriss, Nancy, «Indians in colonial Yucatan: three perspectives», Murdo Macleod y Robert Wasserstrom (eds.), Spaniards and indians in Southeastern Mesoamerica: essays on the history of ethnic relations, Lincoln, University of Nebraska Press, 1983.

Fowler, William, The cultural evolution of ancient nahua civilizations. The Pipil-Nicarao of Central America, Norman y London, University of Oklahoma Press, 1989.

Fuentes y Guzmán, Francisco Antonio de, Historia de Guatemala o Recordación Florida, 2 y 3 vols. Biblioteca de Autores Españoles, núm. 251, 259, Madrid, Editorial Atlas, 1972.

García de Palacio, Diego, «Relación hecha por el Licenciado Palacio al Rey D. Felipe II, en la que describe la Provincia de Guatemala, las costumbres de los indios y otras cosas notables», Colección de documentos inéditos para la historia de Costa Rica, San José de Costa Rica, Imprenta Nacional, Vol. 1, 1881: 1-52.

Lardé y Larín, Jorge, El Salvador. Historia de sus pueblos, villas y ciudades, San Salvador, Ministerio de Cultura, 1957.

Libro Viejo de la Fundación de Guatemala (1524-1530), Guatemala, Academia de Geografía e Historia, 1991.

López Austin, Alfredo y López Luján, Leonardo, El pasado Indígena. Fideicomiso Historia de las Américas, Serie Hacia una Nueva Historia de México, México, Fondo de Cultura Económica, 1996.

López de Velasco, Juan, Geografía y descripción general de las Indias, Biblioteca de Autores Españoles, núm. 248, Madrid, Ediciones Atlas, 1971.

Lovell, George, Conquista y cambio cultural. La sierra de los Cuchumatanes de Guatemala, 1500-1821, Antigua, Centro de Investigaciones de Mesoamérica, 1990. 
Macleod, Murdo, Spanish Central America. A socioeconomic history, 1520-1720, Berkeley, University of California Press, 1973.

Martínez Millán, José (dir.), La corte de Felipe II, Madrid, Alianza Editorial, 1994.

Martínez Millán, José, La corte de Carlos V, Madrid, Sociedad Estatal para la Conmemoración de los Centenarios de Felipe II y Carlos V, 2000.

Menegus, Margarita, «El cacicazgo en Nueva España», Margarita Menegus y Rodolfo Aguirre (coords.), El cacicazgo en Nueva España y Filipinas, México, Centro de Estudios sobre la Universidad y UNAM, 2005: 13-69.

Molina, Carlos, El gobernador de Nicaragua en el siglo XVI: contribución al estudio de la historia del derecho nicaragüense, Sevilla, Escuela de Estudios Hispanoamericanos, 1949.

O'Phelan, Scarlet, Kurakas sin sucesiones. Del cacique al alcalde de indios. Perú y Bolivia 1750-1835, Cuzco, Centro de Estudios Regionales Andinos Bartolomé de Las Casas, 1997.

Pineda, Juan de, Relación de la Provincia de Guatemala, edición de René Acuña, México, UNAM, 1982.

Recopilación de Leyes de los Reynos de las Indias, (1681), 3 vols. Madrid, Consejo de la Hispanidad, 1943.

Remesal, Fray Antonio de, Historia General de las Indias Occidentales y particular de la Gobernación de Chiapa y Guatemala, vol. 1, Biblioteca de Autores Españoles, núm. 175, Madrid, Ediciones Atlas, 1964.

Service, Elman, Los orígenes del estado y de la civilización. El proceso de la evolución cultural, Madrid, Alianza Editorial, 1984.

Sherman, William, Forced native labor in sixteenth-century Central America, Lincoln y Londres, University of Nebraska Press, 1979.

Tanck Estrada, Dorothy, Atlas ilustrado de los pueblos de indios: Nueva España, 1800, México, El Colegio de México, 2005.

Tous, Meritxell, De protagonistas a desaparecidos. Las sociedades indígenas de la Gran Nicoya, siglos XIV a XVII, Managua, Lea Grupo Editorial, 2008.

Vitoria, Francisco de, Relaciones del estado, de los indios y del derecho de la guerra, México, Editorial Porrúa, 1974.

Webre, Stephen, «Poder e ideología: la consolidación del sistema colonial (1542-1700)», Julio Pinto Soria (ed.), Historia general de Centroamérica, Vol. II, Madrid, Sociedad Estatal Quinto Centenario y Facultad Latinoamericana de Ciencias Sociales, 1993: 151-218.

Fecha de recepción: 21-3-2007

Enviado a modificar: $24-4-2007$

Enviado conforme a las normas: 7-2-2008 


\section{CACIQUES AND CABILDOS: THE SOCIO-POLITICAL ORGANIZATION OF THE INDIGENOUS POPULATION IN THE ALCALDÍA MAYOR OF SONSONATE (S. XVI)}

This paper analyzes the mechanisms developed during the sixteenth century by the Pipil group of the Izalcos region to enable the endurance of the basic elements of its pre-Columbian socio-political organization. Its traditional authorities (caciques and principales) played a central role in the adaptation of the ancient system to the newly imposed model, the indigenous cabildo. Despite being completely foreign to the ancient order, this institution was key to the survival and maintenance of the fundamental elements of its traditional socio-political organization.

KeY words: Pipil, Izalco, Alcaldía Mayor of Sonsonate, Socio-political organization. 
